\title{
DEVELOPMENT OF A NOVEL CRAWLER BASED ROBOT FOR MOORING CHAIN CLIMBING
}

\author{
MAHESH DISSANAYAKE \\ London south Bank University \\ 103 Borough Rd, London, SE1 0AA, United Kingdom \\ MD OMAR HOWLADER \\ London South Bank Innovation Centre
}

TWI Ltd, Granta Park, Cambridge CB21 6AL, United Kingdom

TARIQ P. SATTAR

London South Bank Innovation Centre

TWI Ltd, Granta Park, Cambridge CB21 6AL, United Kingdom

TAT-HEAN GAN

Integrity Management Group,

TWI Ltd, Granta Park, Cambridge CB21 6AL, United Kingdom

\section{IVAN PINSON}

NDT section

TWI Ltd, Granta Park, Cambridge CB21 6AL, United Kingdom

\begin{abstract}
Mooring systems experience high tidal waves, storms and harsh environmental conditions. Therefore, ensuring the integrity of mooring chain is important. The aim of the work reported in this paper is to develop a robotic system that performs in-service nondestructive testing of mooring chains. The inspection system is an autonomous device that operates in air as well as underwater. The permanent magnet adhesion crawler robot developed can climb mooring chains at a speed of $42 \mathrm{~cm} /$ minute with a pay load of $50 \mathrm{~N}$. FEA study of the magnetic adhesion module, structural analysis, prototyping and testing of the robot is presented in this paper.
\end{abstract}

Keywords: Mooring chain; Chain Climbing Robot; Crawler Robot; Magnetic adhesion climbing robot. 


\section{Introduction}

\subsection{Mooring Chain Integrity}

With increase of the world's energy consumption, the number of floating oil and gas production systems have (FPS) increased dramatically since the 90's. It is not possible to move most of the floating oil production systems for inspection or repair. Moreover, mooring systems which are used to attach the floating platforms to the seabed often experience high tidal waves, storms and harsh environmental conditions. Therefore, ensuring the integrity of mooring chain is crucial, because single line mooring failure can cost approximately $£ 2 \mathrm{M}-10.5 \mathrm{M}$ [1]. There were 21 accidents due to mooring failures between 2001 and 2011 including 8 multiple mooring chain breaking incidents [2]. Due to a breaking of mooring system (chain), vessel drift, riser rupture, production shutdown and hydrocarbon release can occur. For an example, "Gryphon Alpha" had to spend $\$ 1.8$ billion to resume after it's mooring failure [3]. Replacing mooring chains to inspect the original is expensive and there is a high probability of damage. The mobile crawler robot presented in this paper is able to climb on the mooring chain both in air and water. This entire robotic system consists of four crawler units for locomotion. Only two crawler modules are attached to the body of the mooring chain at a given time using magnetic adhesion while the other two are suspended in air. This is due to 90 degrees phase difference between two adjacent mooring links. As the robot is moving along the chain, alternate set of crawler modules are attached to the link. A novel magnetic flux concentration technique is adopted to optimize the dimension and weight of the adhesion module. This prototype system can successfully travel along vertically aligned mooring chain links. The paper presents the structural design, FEA analyses, motor selection, adhesion force requirements, prototyping of the concept, and experimental testing of a prototype.

\subsection{State of the art of mooring chain inspection systems}

A few attempts to establish a robot mechanism have been made but due to the mechanical complexity of the climbing structure, they were unable to extend the research beyond the initial experimental stage. The "MoorInspect" inchworm climbing robot [4] weighed $450 \mathrm{~kg}$ in air [Internal report] and carried NDT equipment to give a total weight of $750 \mathrm{~kg}$. The ICARE is another heavy climbing robot for subsea cleaning and inspection of anchor lines [5] which uses a humanlike climbing method with two paws. Heavy robots are not easily deployable in offshore environments with manipulation issues while climbing over the catenary curves, etc. These robots are deployed manually by using divers and boats. 
Therefore, it is not practically possible to handle a large amount of a weight in a small boat with divers (without lifting equipment). A novel automated ultrasonic inspection system to investigate mooring chains during the manufacturing process is presented in [6]. This system inspects welding joints on chain links during the manufacturing stage. The main aim of the project "chain test" was to develop a system which can be operated without bringing the chain on-board [7]. A crawling mechanism was developed but according to the internal report of the project the robot was unable to perform as expected.

\subsection{Design requirements}

Mooring chains are often subjected to high environmental changes due to tidal waves, wind, etc. Therefore, it is required to design an automated/robotic system that has a tolerance to in situ conditions. The mooring chain links shown are curved and mostly rusted and with uneven surfaces (Figure 1), so the system should be able to handle the physical nature of the mooring chain. For this research, a stud-less mooring chain is used with the dimensions shown in figure 1. The robot should be easily deployed and retrieved. Therefore, it is necessary to make the system lightweight (expected maximum structural weight $30 \mathrm{~kg}$ ) and be able to carry payload of $12 \mathrm{~kg}$ or more. The adhesion mechanism for vertical climbing should be sufficient to keep the robot attached to the chain during motion. Moreover, due to the amphibious nature of mooring chains, robotic and automation methods need to be selected carefully.

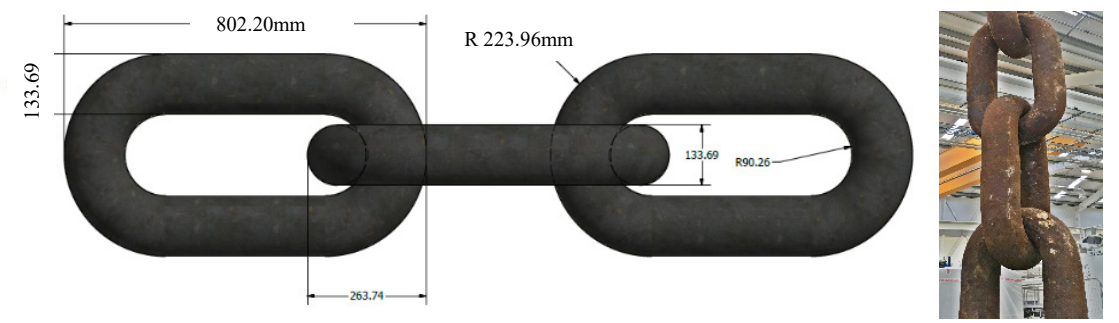

Figure 1. Mooring chain and dimensions (which used in this research)

\section{Design}

\subsection{Concept}

There is one set of two tracked wheels that move on one link while another set moves on an adjacent orthogonal link (Figure 2\&3). Therefore, each orthogonal set of crawlers wheels enables the robot to move along the chain. A permanent magnet system is employed to design an underwater adhesion system 
with zero energy requirements. According the design concept, 4 tracked crawlers are activated during to the entire climbing and that creates a "peel off" effect which helps crawlers to leave the surface at the end of a chain link. In addition to that, at a given location, at least 2 crawlers are in contact with the chain link so, it forces the structure to crawl in a linier trajectory.

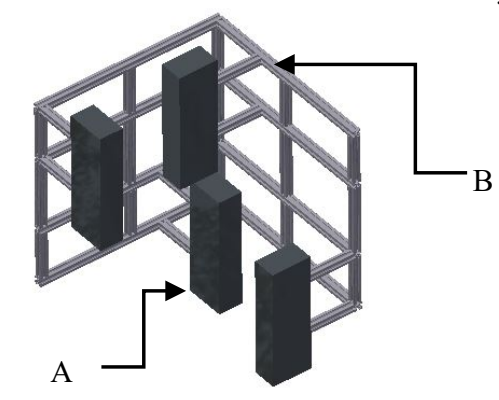

A- Crawler, B- "L" shaped Aluminum frame

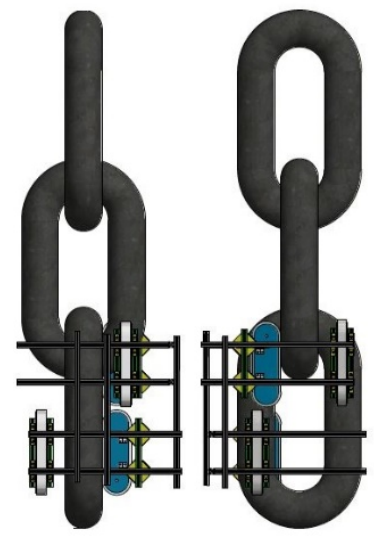

Figure 2. Frame

Figure 3. Design and crawler positioning on the chain

\subsection{Motors}

Motor and the gearbox are required to generate enough torque $\left[\mathrm{T}_{\mathrm{Mot}}\right]$ to pull the structure upward against the structural downwards force $\left[F_{s}\right]$ and magnet adhesion force $\left[F_{M}\right]$. Speed of the robot $\left[\mathrm{S}_{\mathrm{r}}\right]$ depends on the output RPM of the gearbox-motor combination $\left[\mathrm{RPM}_{\mathrm{g}+\mathrm{m}}\right]$ and crawler's effective radius $\left[\mathrm{r}_{\mathrm{C}}\right]$

$\mathrm{T}_{\mathrm{Mot}} \geq\left[\mathrm{F}_{\mathrm{s}}+\mathrm{F}_{\mathrm{M}}\right] \times \mathrm{r}_{\mathrm{C}}$

$\mathrm{S}_{\mathrm{r}}=\mathrm{RPM}_{\mathrm{g}+\mathrm{m}} \times\left[2 \pi \times \mathrm{r}_{\mathrm{C}}\right]$

According to equation (1), $\mathrm{T}_{\mathrm{Mot}} \geq 33.33 \mathrm{Nm}$. When considering climbing, at least two crawler tracks are in contact with the chain surface. Therefore, each crawler should produce at least 16.667 Nm torque. According to equation (2), speed of the robot is $42 \mathrm{~cm} / \mathrm{min}$ (which is suitable for inspection purposes).

\subsection{Frame and crawler}

The robot should be placed on a mooring chain with minimum effort. Therefore, minimizing the weight of the robot (less than $30 \mathrm{~kg}$ ) and deployment ability were considered during the design of the main structure. To achieve the above requirements, "L" shaped frame (figure 5) was selected and constructed with aluminium extrusions. A study was carried out to identify the stress and frame deformations by using 'Comsol Multiphysics' and 'Inventor stress analysing'. Maximum frame deformation without a pay load is $0.2411 \mathrm{~mm}$ and 
maximum stress is $15.04 \mathrm{MPa}$. A structural analysis study was performed with various pay loads (Figure 4). The robot locomotion mechanisms use tracks to provide sufficient traction on rough and uneven chain links (due to corrosion and in-situ conditions).

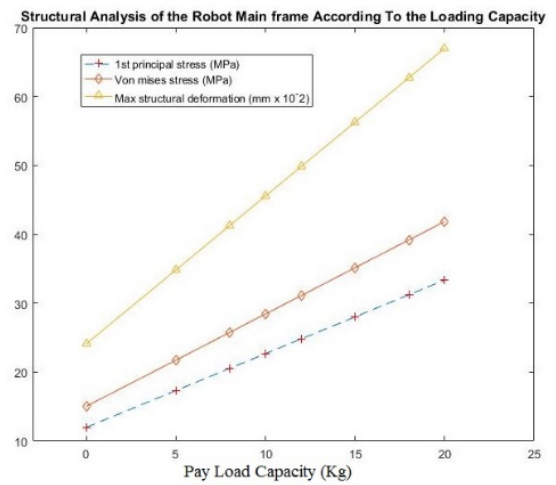

Figure 4. Frame deformation and stress

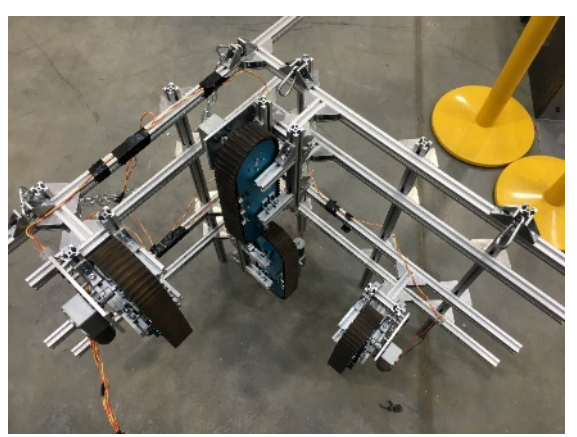

Figure 5. "L" shaped robot frame

\subsection{Magnets}

When the robot's parameters are weight $(w)$, coefficient of friction $(\mu)$, vertical plane's inclination $(\alpha)$, required adhesion force $\left(F_{a}\right)$ can be calculated by using equation (3) [8].

$F a \frac{W \times \sin (\alpha)}{\mu}-w \times \operatorname{Cos}(\alpha)$

To simulate the adhesive force of magnets, required magnet force $(191.23 \mathrm{~N})$ was obtained from the above equation. Magnets were kept at $9 \mathrm{~mm}$ distance from the link surface. Following data was used during the stationary simulation in COMSOL Multiphysics (Table 1 and Figure 6). Previous research [9] was used as the basis of the following experiment. A $219.16 \mathrm{~N}$ force was produced by the experimental magnet (N52, neodymium) arrangement shown in figure 7.

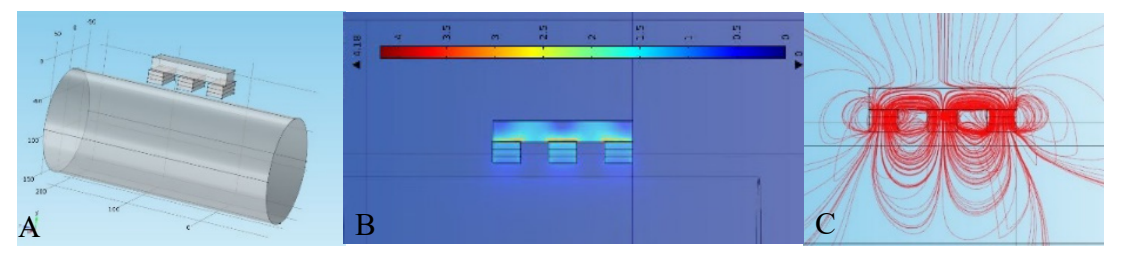

A- Magnet -chain model, B- Magnetic flux density, C- Flux lines

Figure 6. COMSOL FEA results of the magnet design 
Table 1. Magnets simulation parameters.

\begin{tabular}{cc}
\hline parameter & Parameter value \\
\hline Magnet Relative permeability & 1.05 \\
Residual Flux Density (Br) & $1.45 \mathrm{~T}$ \\
& L 40mm, W $20 \mathrm{~mm}$ \\
Magnet size / back plate size & H $5 \mathrm{~mm} / \mathrm{L} 100 \mathrm{~mm}$ \\
&, H $15 \mathrm{~mm}, \mathrm{~W}$ \\
Iron relative permeability & $40 \mathrm{~mm}$ \\
Coefficient of friction & 4000 \\
\hline
\end{tabular}

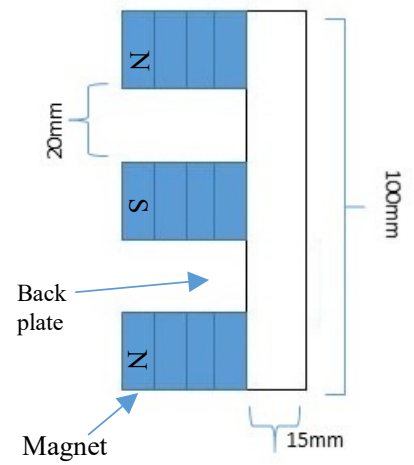

Figure 7. Purposed magnet arrangement

\section{Experimental results}

\subsection{Magnet experiment}

The test rig in figure 8 was used to validate magnet adhesion results simulated in FEA studies. Experimental results were very close to the simulation results. Experimental adhesion results gave higher adhesion forces than the simulations. Maximum difference between results was $13.44 \mathrm{~N}$.
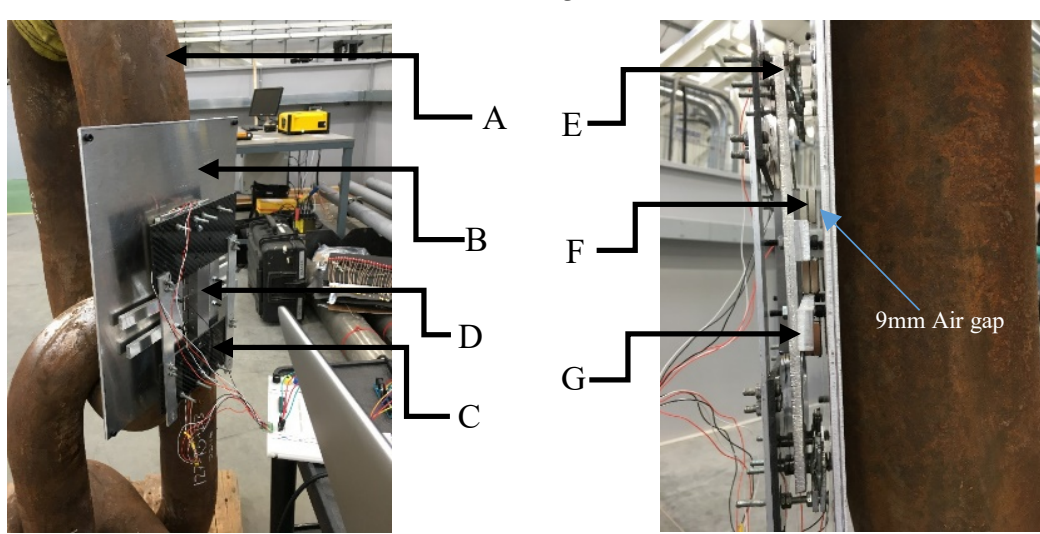

A-Mooring chain, B-5mm Aluminum plate, C-Carbon fiber test rig, D-Iron Back plate and magnets, E-load cells , F- Magnets, G- spacers

Figure 8. Magnetic force measurements using the experimental test rig 


\section{Prototyping and testing}

The L shaped main frame was created and the four crawlers actuated with DC motors were attached to the frame. The climbing test was conducted (Figure 9).

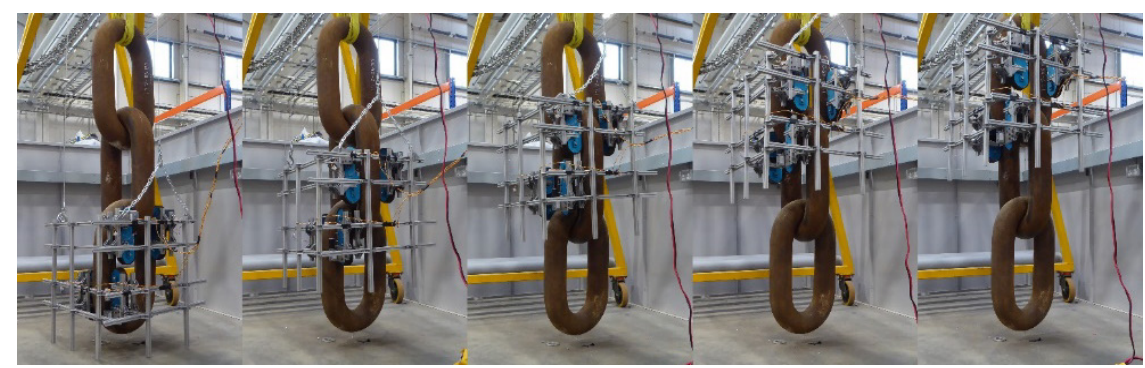

Figure 9. Mooring chain climbing sequence

At the current stage of development, a payload was not attached but a stability check was performed with an external applied force by adding a set of weights. The crawler robot was able to stay attached to the chain clinks with up to $50 \mathrm{~N}$ of external payload (Figure 10). The robot was able to move along chain links with the speed of $42 \mathrm{~cm} / \mathrm{min}$ as calculated before.

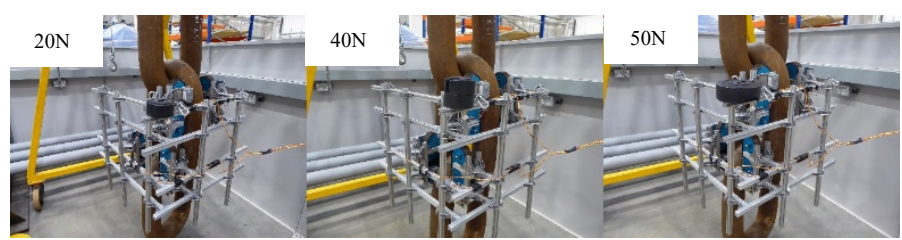

Figure 10. Stability test with external loads

\section{Conclusions}

A novel lightweight, fast moving mooring chain climbing robot system has been prototyped that can be easily deployed and retrieved. Structural analysis and validation experiments were carried out by using CAD design software (Autodesk Inventor) and FEA software (COMSOL) to develop a robust structure. A neodymium permanent magnet adhesion system was optimized with COMSOL and used in this robot to create the necessary addition forces. The robot system was tested in a laboratory on a three-link chain segment to study its climbing capability and stability. In conclusion, the feasibility of using a crawler with orthogonal arrangement of tracked wheels to climb on mooring chains has been established. 


\section{Acknowledgement}

This publication was made possible by the sponsorship and support of TWI Ltd and London South Bank Innovation Center. The work was enabled through, and undertaken at, the National Structural Integrity Research Centre (NSIRC), a postgraduate engineering facility for industry-led research into structural integrity established and managed by TWI through a network of both national and international Universities.

\section{References}

1. N. D. E. Limited, "Floating production system -JIP FPS mooring integrity," Health And Safety Executive, Aberdeen, 2016.

2. M. Kai-tung, A. Duggal, P. Smedley, D. L'Hostis and S. Hongbo, " $A$ Historical review on Integrity issues of permanent mooring systems," in Houston, Texas, Offshore Technology Conference, 2013.

3. P. Elman, . J. Bramande, . E. Elletson and K. Pinheiro, "Reducing Uncertainty Through the Use of Mooring Line Monitoring," in Offshore Technology Conference, Rio de Janeiro, Brazil, 2013.

4. T.P. Sattar, A.Ruiz Garcia, M. Sanz Correa, M., \& B.S. Filloy Rodriguez, Inspection of floating platform mooring chains with a climbing robot. 17th International Conference on Climbing and Walking Robots and the Support Technologies for Mobile Machines (CLAWAR 2014), Poland.

5. P. Weiss, F. Andritsos, F. Schom and A. Fidani, "Innovative Robotic Solutions for the Survey and Certification of Ships and Mobile Offshore Units," in COMPIT, Siguenza, Spain, 2004.

6. J. L. García, E. García, C. M. Suárez, . D. Blanco and . N. Beltrán, "Automated Off-shore studless chain inspection system," in 16th WCNDT World Conference on NDT, Montreal, Canada, 2004.

7. S. Williams, "cordis.europa.eu," 14 March 2008. [Online]. Available: http://cordis.europa.eu/docs/publications/1216/121625181-6_en.pdf. [Accessed 10 December 2015].

8. M. O. F. Howlader and T. . P. Sattar, "Finite Element Analysis based Optimization of Magnetic Adhesion Module for Concrete Wall Climbing Robot," International Journal of Advanced Computer Science and Applications, vol. 6, no. 8, pp. 8-18, 2015.

9. M. O. F. Howlader and T. P. Sattar, "Development of magnetic adhesion based climbing robot for non-destructive testing," in Computer Science and Electronic Engineering Conference (CEEC), 2015. 